\title{
Síndrome medular agudo causado por hematoma epidural tras punción anestésica
}

\author{
Acute medular syndrome caused by epidural hematoma after \\ anesthetic puncture
}

María Alfonso García ${ }^{1}$, Alessandro Bianchi ${ }^{1}$, Natalia Pujol Cano ${ }^{1}$, Beatriz Miriam Rodríguez Chikri $^{1}$, Marina Jiménez Segovia ${ }^{1}$ y Francesc Xavier González Argente ${ }^{1}$

Paciente mujer de 85 años, anticoagulada por fibrilación auricular, intervenida de forma urgente por obstrucción de yeyuno medio condicionada por colección intraabdominal. Se procede a colocación de catéter epidural para perfusión continua de analgésicos y se procede a laparotomía exploradora, hallando absceso intraabdominal por perforación por espina de pescado, realizándose resección de yeyuno y anastomosis latero-lateral mecánica.

El segundo día postoperatorio la paciente presen- ta monoplejia inferior derecha, paresia 3/5 izquierda y afectación esfinteriana. Se realiza RM evidenciando hematoma epidural de $11 \mathrm{~cm}$ x $13 \mathrm{~cm}$ que se extiende de D11 a L2 con efecto masa sobre cono medular y raíces de cola de caballo (Figuras 1 y 2). Se realiza laminectomía de D11 a L2 con evacuación de hematoma. La paciente presenta una evolución tórpida con establecimiento de clínica neurológica. Es alta al mes de la intervención presentando mínima mejoría respecto a la clínica inicial.
${ }^{1}$ Hospital Universitario Son Espases. Palma de Mallorca, España.

Recibido el 25 de diciembre de 2019 y aceptado para publicación el 30 de diciembre de 2019.

Correspondencia a: Dra. María Alfonso García maria.alfonsogarcia@ssib.es

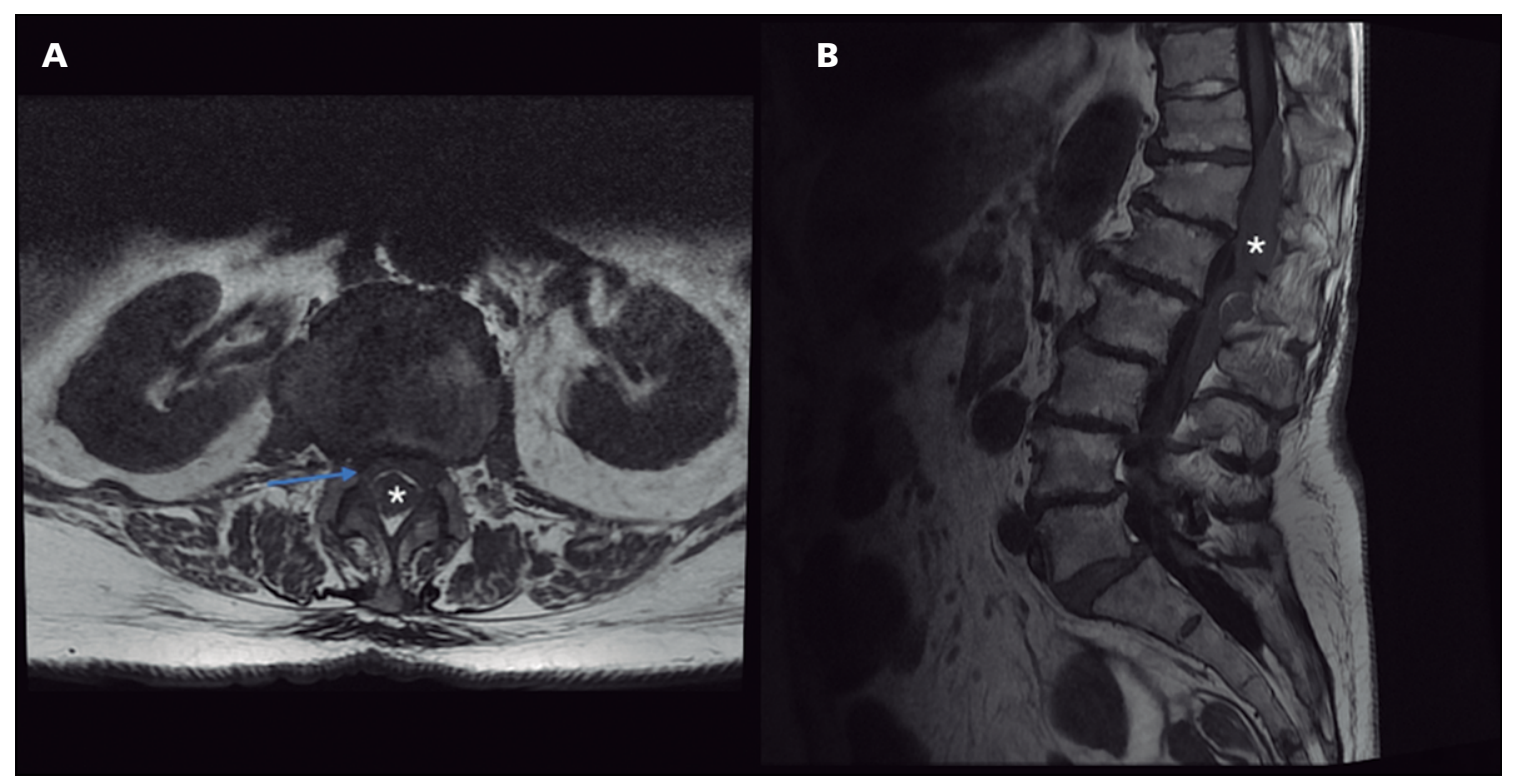

Figura 1. RM de columna lumbar axial y sagital. *hematoma epidural. 


\section{IMÁGENES Y CIRUGÍA}

Figura 2. RM de columna lumbar axial y sagital. *hematoma epidural.

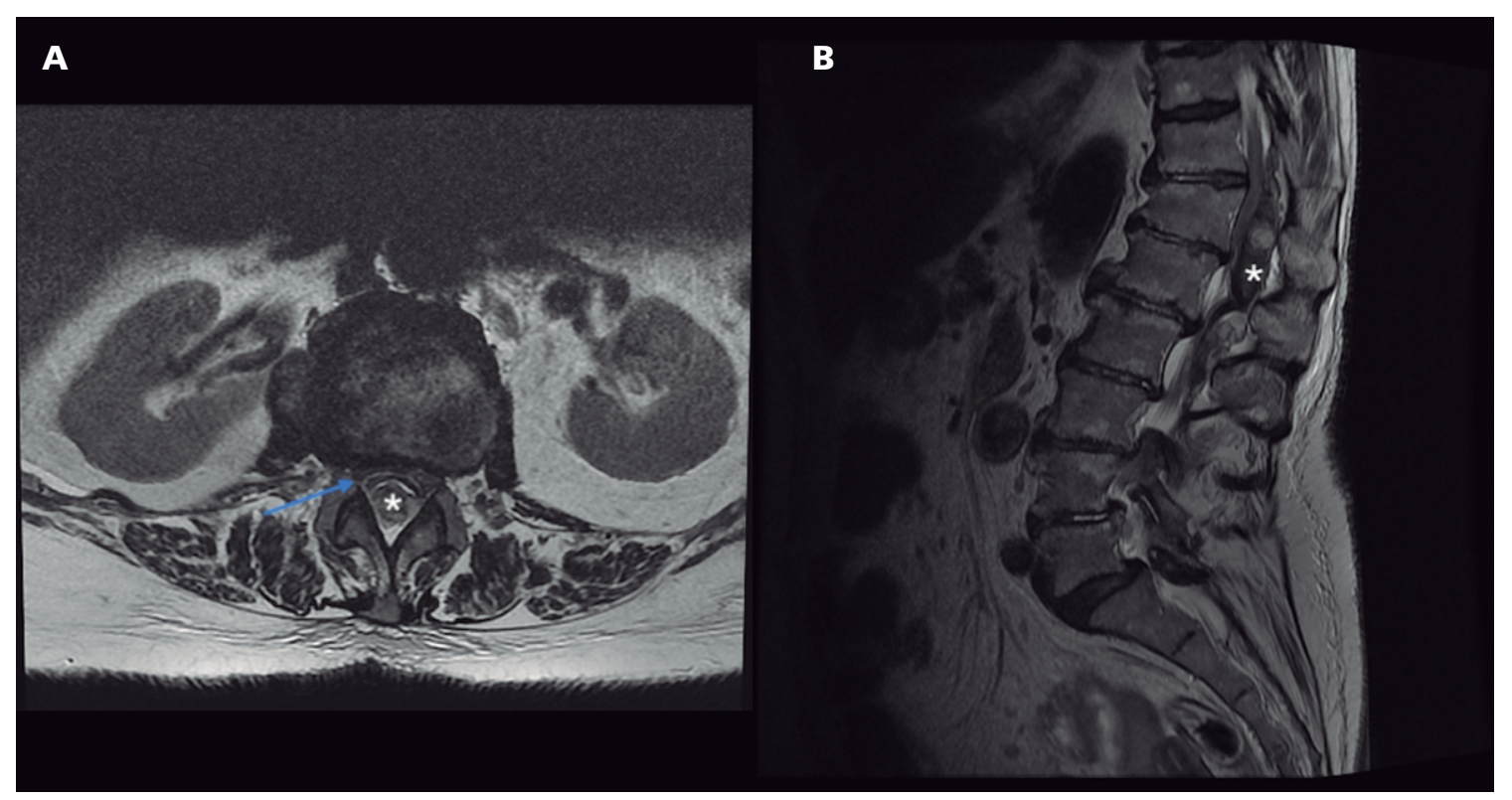

La combinación de anestesia general con analgesia epidural se considera como el gold-standard para la cirugía abdominal por vía laparotómica. Antes la aparición de síntomas neurológicos en el postoperatorio inmediato de pacientes portadores de catéter epidural es preciso sospechar de complicaciones relacionadas con el mismo, como el daño directo de la médula espinal, hematoma epidural, abscesos o meningitis.

\section{Responsabilidades éticas}

Protección de personas y animales. Los autores declaran que para esta investigación no se han realizado experimentos en seres humanos ni en animales.

Confidencialidad de los datos. Los autores declaran que en este artículo no aparecen datos de pacientes.

Conflictos de interés: no hay. 